Taghreed Alhaidari*, Nazar Amso, Taqi Mohammed Jawad, Ulfat Alnakkash, Faris Khazaal, Ahmed Alnaaimi, Timothy Pickles, Rebecca Playle, Robert Istepanian, Nada Philip, John W. Gregory and Thamer Al Hilfi

\title{
Feasibility and acceptability of text messaging to support antenatal healthcare in Iraqi pregnant women: a pilot study
}

DOI 10.1515/jpm-2016-0127

Received April 11, 2016. Accepted January 31, 2017.

\section{Abstract}

Objective: To determine the feasibility and acceptability of mobile health technology and its potential to improve antenatal care (ANC) services in Iraq.

Methods: This was a controlled experimental study conducted at primary health care centers. One hundred pregnant women who attended those centres for ANC were exposed to weekly text messages varying in content, depending on the week of gestation, while 150 women were recruited for the unexposed group. The number of ANC visits in the intervention and control groups, was the main outcome measure. The Mann-Whitney test and the

\footnotetext{
*Corresponding author: Dr. Taghreed Alhaidari, Scientific Unit, Al Kindy College of Medicine, University of Baghdad,

P.O. Box: 19033, Al Dhubbat, Baghdad, Iraq, Tel.: +964 7701715028 , +964 7906216647, E-mail: Taghreed.alhaidari@kmc.uobaghdad. edu.iq; taghreed.alhaidari@gmail.com

Nazar Amso: Institute of Translation, Innovation, Methodology and Engagement, School of Medicine, Cardiff University, Cardiff, UK Taqi Mohammed Jawad: Community Medicine Department, $\mathrm{MOH}$, Baghdad, Iraq

Ulfat Alnakkash: Obstetrical and Gynaecological Department, Elwyia Maternity Teaching Hospital, Baghdad, Iraq

Faris Khazaal: Medical Department, Alkindy College of Medicine, University of Baghdad, Baghdad, Iraq

Ahmed Alnaaimi: Community Medicine Department, Baghdad Medical College, University of Baghdad, Baghdad, Iraq

Timothy Pickles and Rebecca Playle: Centre for Trials Research, College of Biomedical and Life Sciences, Cardiff University, Cardiff, UK

Robert Istepanian: Department of Electrical and Electronic Engineering, Imperial College, London, UK

Nada Philip: Faculty of Science, Engineering and Computing, Kingston University, London, UK

John W. Gregory: Institute of Molecular and Experimental Medicine, School of Medicine, Cardiff University, Cardiff, UK

Thamer Al Hilfi: Community Medicine Department, Al Kindy College of Medicine, University of Baghdad, Baghdad, Iraq
}

Poisson regression model were the two main statistical tests used.

Results: More than $85 \%$ of recipients were in agreement with the following statements: "the client recommends this program for other pregnant women", "personal rating for the message as a whole" and "obtained benefit from the messages". There was a statistically significant increase in the median number of antenatal clinic visits from two to four per pregnancy, in addition to being relatively of low cost, and could be provided for a larger population with not much difference in the efforts.

Conclusions: Text messaging is feasible, low cost and reasonably acceptable to Iraqi pregnant women, and encourages their ANC visits.

Keywords: Antenatal care; developing country; pregnancy; primary care; text messaging; women.

\section{Introduction}

There are 5.4 billion mobile subscriptions in the developing world - that is $78 \%$ of all global subscriptions. Mobile penetration in the developing world has grown to $90.2 \%$, but there is still potential for growth [1]. The introduction of information and communication technologies (ICT) in healthcare, especially the application of mobile technology (m-Health), has already transformed healthcare delivery by making it more accessible and affordable across the developing world where health services are often inadequate, inaccessible, costly, dysfunctional, low in quality and unresponsive to the needs of clients [2, 3]. This health need, in accordance with the World Health Organization (WHO) report, will remain unmet until at least 2050; in this context, through its reach and low cost, $\mathrm{m}$-Health has emerged as a viable solution $[4,5]$.

There are some online resources for pregnant women available through the Internet, but Iraqi women may lack proficiency not only in English but also in basic computing [6]. Moreover, text is better suited to push technology than the Internet [7]. 
Iraq's healthcare system has suffered major setbacks due to decades of war and economic sanctions. Furthermore, access to healthcare has been further affected by recent instability and ongoing strife. Over the past few years, the Ministry of Health $(\mathrm{MOH})$ policy has been to restructure the health system based on primary healthcare (PHC), but the services currently provided at the PHC level only partially meet the health needs of the population. This situation, combined with a low perceived quality of care, has led the population to seek care at secondary and tertiary levels, thereby bypassing primary care [8].

$\mathrm{m}$-Health is an evolving approach that can be defined as "mobile computing, medical sensor and communications technologies for healthcare" [9]. Numerous m-Health pilot projects throughout the developing world have demonstrated key benefits in healthcare outcomes, with implications for healthcare policy [10]. The aim of this project was to introduce an m-Health service to routine antenatal care (ANC) in a PHC setting in a developing country like Iraq, as the mobile phone is a widely (almost universally) used communication device there.

The study objectives were to:

1. Determine the feasibility and acceptability of $\mathrm{m}$-Health technology in antenatal healthcare.

2. Measure satisfaction with text messaging services.

3. Assess the effect of m-Health technology on the count of antenatal visits.

4. Study the association of selected explanatory variables [employment status, educational level, residence type, financial support for the family, healthcare provider, availability of transport facility, ownership of a mobile phone, usage of the Internet to look for health information, current pregnancy status (planned or not) and family history of congenital anomalies] with satisfaction score (positive impact score).

\section{Materials and methods}

The project was designed as a controlled experimental study, where an intervention group was exposed to text messages on a weekly basis and the results were compared to those from an unexposed control group. This study was approved by the Ethical and Scientific Committee of Al-Kindy College of Medicine and was undertaken from May 2010 to October 2011. The study was executed in the antenatal clinic that links to Al Elwiya Maternity Teaching Hospital.

A consultant obstetrician designed text messages and supervised the logistics of posting them. The suggested text messages underwent face validity that was assessed by a panel of three obstetricians who spoke the native Arabic language and by 20 pregnant patients as part of a pilot project (unpublished work).

A total of 100 women were recruited for the intervention group and another 150 were recruited for the unexposed (control) group.
All the selected females gave their informed consent to participate in the study. Three pregnant women from the intervention group and four from the control group changed their residency place and therefore were lost to follow-up and were, thus, excluded from the statistical analysis. Both groups were selected using a systematic random sample approach in a clinical setting. The average daily workload in an ANC clinic is 60 pregnant females and the working week extends from Sunday to Thursday. The sampling periodicity was set at every $5^{\text {th }}$ client, allowing for a total of 12 study subjects per working day. Out of each five; the first two were selected in the intervention group and the following three were selected in the control group. This sampling strategy was repeated in the same pattern during the work day. The total sample size was recruited over the course of 5 weeks.

Data were collected from the intervention group using a predesigned structured questionnaire in a personal interview setting.

A weekly text message was sent to each participant in the intervention group starting from the $6^{\text {th }}$ week of pregnancy. In order to determine the messages sent, client preferences for three types of message themes were explored. These themes included general health messages, those encouraging visits to the PHC center (PHCC) and nutritional advice/lifestyle education. The preference variable was simply a dichotomous one with two choices only for each theme (preferred/not preferred), with the ability to select more than one theme. As a result, the messages sent included 1) reminders to visit the PHCC, 2) general health instructions and 3) dietary advice and lifestyle educational messages. These messages were sent through a website for short message services, "forat-sms.com", which can generate multiple messages at the same time.

The pre-prepared, validated, Arabic-language messages were sent each Friday between $4 \mathrm{pm}$ and $6 \mathrm{pm}$ as preferred by most of the participants and the sender, as is it is an official holiday. The total cost for sending these messages was $\$ 159.885$, about 2 cents per message.

The impact of the program was assessed by the degree of satisfaction with its content and process. A total of 11 items were designed to measure the content and process of mobile phone messages. Client satisfaction with these items was explored in the intervention group using a Likert-type scale, which consisted of 5 grades measuring respondents' agreement with the presented items (ranging from 1 for strongly disagree to a maximum of 5 for strongly agree). The scores on these 11 items were totaled and then presented on a scale with a maximum of 10 grades for clarity and simplicity. For a specific study subject, the score of each of the 11 items was added together, allowing for a maximum score of $55(11 \times 5)$ if the subject was highly satisfied with all 11 items (obtaining a score of 5 for "highly satisfied" in each). The resulting total score was weighted to a maximum of 10 by multiplying by a factor of $10 / 55$. The resulting score was called the "total score of positive impact for the intervention program".

The intervention group participants were also provided with two mobile phone numbers, one for each of the two major mobile phone service providers (Zain Telecom and Asiacell Telecom) to answer any enquiries they had during pregnancy. A total of 314 calls (the average duration for each call was $2.4 \mathrm{~min}$ ) were received, and confidentiality was ensured.

Both study groups received the same standard healthcare in the clinic. The only advantage of the intervention group was the weekly texts they received and access to the help line.

In addition to collecting demographic information on participants, we calculated the crowding index by dividing household size (count of subjects living in the residence) by count of rooms (excluding the kitchen and bath). 


\section{Statistical analysis}

Data analysis was carried out using IBM SPSS v.20 software (International Business Machines Corp., Armonk, NY, USA). The statistical significance, strength and direction of linear correlation between the two quantitative variables were assessed by Spearman's rank correlation coefficient. The statistical significance of difference in mean score between the two groups was tested by an independent samples $t$-test. The difference in median count of visits and educational level between the two groups was tested by the Mann-Whitney test.

A Poisson regression model with the count of ANC visits as the dependent (outcome or response) variable was used to measure the net effect of SMS intervention.

\section{Results}

There were no major differences between the intervention and control groups regarding mean age (26.5, SD 6.1 years), median parity (1), employment status (about three quarters unemployed) and gestational age at the time of delivery. The educational level was higher in the control group (Table 1).

\section{Description of the intervention (SMS) group}

Financial support for the family was provided solely by the husband for $78.4 \%$ of the cases. Only $10.3 \%$ of the subjects used the health center as the sole healthcare provider. Transportation facilities were available to $55.7 \%$ of the intervention group. A high proportion (86.6\%) of the intervention group owned a personal mobile and $85.6 \%$ stated that the current pregnancy was planned and therefore desirable. A small proportion (10.3\%) used the Internet to look for health information and $6.2 \%$ reported a family history of congenital anomalies.

Three types of client preferences for the message themes were explored. General health messages were

Table 1: Educational level by group.

\begin{tabular}{lrrrrr}
\hline & \multicolumn{2}{r}{$\begin{array}{r}\text { Controls } \\
(\mathrm{n}=146)\end{array}$} & & $\begin{array}{r}\text { Intervention } \\
(\mathrm{n}=97)\end{array}$ \\
\cline { 2 - 3 } \cline { 6 - 7 } & $\mathbf{n}$ & $\%$ & & $\mathbf{n}$ & $\%$ \\
\hline Illiterate & 3 & 2.1 & & 4 & 4.1 \\
Able to read and write & 0 & 0 & 10 & 10.3 \\
Primary school & 40 & 27.4 & 33 & 34 \\
Intermediate school & 34 & 23.3 & & 21 & 21.6 \\
Secondary school & 22 & 15.1 & & 1 & 1 \\
Higher education (college/institute) & 47 & 32.2 & & 28 & 28.9 \\
\hline
\end{tabular}

preferred by $22.7 \%$ of the subjects, while messages encouraging visits to the PHCC were preferred by $4.1 \%$ of the subjects, and nutritional advice and lifestyle education as themes were preferred by $14.4 \%$ of the cases. The remaining $58.8 \%$ liked all three types of message themes.

\section{Measuring the impact of the electronic health experiment}

As shown in Table 2, the frequency of subjects with high satisfaction (agree/strongly agree with the tested item) was highest (>85\%) for the following three items: "The client recommends this program for other pregnant women", "Personal rating for the message as a whole" and "Obtained benefit from the messages". The items with lowest frequency of subjects with high satisfaction $(<70 \%)$ were "Receiving the message in the proper time of the day" and "Messages encouraged the client to visit the PHCC at the scheduled time".

\section{Phone calls by members of the intervention group to a healthcare provider}

More than half (60.8\%) made at least one phone call; of these, $50.5 \%$ were related to pregnancy problems, $32 \%$ to content of an SMS message, 34\% to labor and $28.9 \%$ to puerperium. A total of 314 phone calls were

Table 2: The frequency of subjects who agree/strongly agree with selected items measuring satisfaction with the SMS experiment in the intervention group.

\begin{tabular}{lrrr}
\hline $\mathbf{n}=97$ & $\mathbf{n}$ & $\%$ \\
\hline $\begin{array}{l}\text { The client recommends this program for other pregnant } \\
\text { women }\end{array}$ & 88 & 90.7 \\
$\begin{array}{l}\text { Personal rating for the message as a whole } \\
\text { Obtained benefit from the messages }\end{array}$ & 86 & 88.7 \\
$\begin{array}{l}\text { Would like these messages to be repeated in } \\
\text { subsequent pregnancies }\end{array}$ & 80 & 82.5 \\
$\begin{array}{l}\text { Would advise their friends to be engaged in the same } \\
\text { program }\end{array}$ & 77 & 79.4 \\
$\begin{array}{l}\text { Satisfied with the messages } \\
\text { The program made the client feel supported during }\end{array}$ & 75 & 77.3 \\
$\begin{array}{l}\text { pregnancy } \\
\text { Messages are understandable }\end{array}$ & 73 & 75.3 \\
$\begin{array}{l}\text { The program relieved the client's anxiety during pregnancy } \\
\text { Received the message at an appropriate time of the day }\end{array}$ & 71 & 73.2 & 67.0 \\
Messages encouraged the client to visit the PHCC at the & 58 & 59.8 \\
\begin{tabular}{l} 
scheduled time \\
\hline
\end{tabular} & & \\
\hline
\end{tabular}


received from the intervention group; those relating to pregnancy problems constituted the highest proportion of the total calls (41.1\%) and to a lesser extent were those related to labor, content of the messages and puerperium (Table 3).

Only the intervention subjects were given the choice to call their healthcare provider as part of this study. The text messages received periodically by the client acted as a cue for the females to contact their healthcare provider to discuss pregnancy-related problems or the content of the messages. It seemed that the tested intervention facilitated easier doctor-patient communication and interaction. This type of communication was not practiced in the control group.

\section{Factors associated with score of the positive impact of the program (satisfaction)}

No statistically significant linear correlations were observed between selected quantitative or ordinal level explanatory variables (age, educational level, crowding index, parity, count of ANC visits) and the total score of the positive impact of the program (satisfaction). All the calculated linear correlation coefficients were $<0.1$ in magnitude and not statistically significant. In addition, dichotomous explanatory variables related to socioeconomic status (employment status, residence type, financial support for the family being mutually shared by the wife, type of healthcare provider, availability of transport facility, personal mobile ownership, using the Internet to look for health information, current pregnancy being planned and making at least one phone call to the support center) also had no significant association with the mean total score of the positive impact of the program (satisfaction). Only one exception was noted for having a positive association, "family history of congenital anomalies", which was associated with a significantly higher mean total score compared to those with no such history, as shown in Table 4.

\section{The number of ANC visits as an outcome}

The use of text message services to provide health-related information in a PHC context (ANC) was associated with a statistically significant increase in the median count of ANC visits, from two in the unexposed controls to four in the intervention group, as can be seen in Table 5 .

\section{Effect of intervention on the ANC visit}

A Poisson regression model with the count of ANC visits as the response (dependent) variable and the effect of intervention compared to unexposed controls in addition to age, parity and educational level as the explanatory (independent variables) was investigated, and neither age nor parity were found to be statistically significant, as shown in Table 6. The intervention and educational level appear to influence the number of visits (more education/fewer visits).

\section{Discussion}

There are up to 358,000 maternal deaths each year in pregnancy and childbirth. Unlike in the developed world, the risk of maternal death in Iraq is still high; in 20062007 , the figure was estimated to be 84 per 100,000 by the WHO, adjusted to 74 in 2012 by UNICEF. One of the WHO key working areas is strengthening health systems and promoting interventions focusing on policies and strategies such as $m$-Health [11, 12]. Moreover, the slow progress and funding constraints in attaining the Millennium Development Goals for child and maternal health encourage harnessing innovative measures, such as m-Health, to address these public health priorities [13]. The issue of competing health system priorities has consistently been rated as the greatest barrier to the adoption of $\mathrm{m}$-Health in various countries [14].

Whilst mobile phone usage is rapidly growing in Iraq, there is still limited use of the Internet, especially among

Table 3: The frequency distribution of total phone calls by its type.

\begin{tabular}{|c|c|c|c|c|}
\hline & Mean count of calls per person & SD & Sum & $\%$ of total calls \\
\hline Count of phone calls related to pregnancy problems & 1.3 & 1.55 & 130 & 41.4 \\
\hline Count of phone calls related to labor & 0.9 & 1.35 & 85 & 27.1 \\
\hline Count of phone calls related to content of SMS message & 0.5 & 0.86 & 50 & 15.9 \\
\hline Count of phone calls related to puerperium & 0.5 & 0.90 & 49 & 15.6 \\
\hline Count of total phone calls & 3.2 & 3.34 & 314 & 100 \\
\hline
\end{tabular}


Table 4: Mean total score for the positive impact of the intervention program by selected explanatory variables.

\begin{tabular}{|c|c|c|c|c|c|}
\hline & $\mathbf{n}$ & Mean (SD) & Difference in means & $95 \% \mathrm{Cl}$ & P-value \\
\hline \multicolumn{6}{|l|}{ Employment status } \\
\hline Unemployed (students/housewives) & 76 & $8.4(0.99)$ & 0.01 & -0.46 to 0.49 & 0.954 \\
\hline Government employee & 21 & $8.4(0.87)$ & & & \\
\hline \multicolumn{6}{|l|}{ Educational level } \\
\hline Primary school and below & 47 & $8.4(0.97)$ & -0.02 & -0.41 to 0.37 & 0.931 \\
\hline Intermediate school and above & 50 & $8.4(0.97)$ & & & \\
\hline \multicolumn{6}{|l|}{ Residence type } \\
\hline Living with parents & 51 & $8.4(1.02)$ & 0.00 & -0.39 to 0.39 & 0.997 \\
\hline Separate (individual) residence & 46 & $8.4(0.91)$ & & & \\
\hline \multicolumn{6}{|l|}{ Financial support for the family } \\
\hline Husband & 76 & $8.4(1.00)$ & 0.08 & -0.40 to 0.55 & 0.755 \\
\hline Both (husband and wife) & 21 & $8.3(0.86)$ & & & \\
\hline \multicolumn{6}{|l|}{ Healthcare provider } \\
\hline Both (private sector and health centre) & 87 & $8.4(0.98)$ & -0.23 & -0.87 to 0.41 & 0.473 \\
\hline Health centre & 10 & $8.6(0.84)$ & & & \\
\hline \multicolumn{6}{|l|}{ Availability of transport facility } \\
\hline Not available & 43 & $8.4(0.93)$ & 0.05 & -0.35 to 0.44 & 0.808 \\
\hline Available & 54 & $8.4(1.00)$ & & & \\
\hline \multicolumn{6}{|l|}{ Owns a personal mobile } \\
\hline Getting the message through a third party mobile phone & 13 & $8.3(1.03)$ & -0.10 & -0.67 to 0.48 & 0.737 \\
\hline Personal mobile available & 84 & $8.4(0.96)$ & & & \\
\hline \multicolumn{6}{|l|}{ Uses the Internet to look for health information } \\
\hline Negative & 87 & $8.3(0.96)$ & -0.57 & -1.20 to 0.07 & 0.078 \\
\hline Positive & 10 & $8.9(0.88)$ & & & \\
\hline \multicolumn{6}{|l|}{ Current pregnancy is planned } \\
\hline Unplanned & 14 & $8.2(1.19)$ & -0.21 & -0.76 to 0.35 & 0.459 \\
\hline Planned & 83 & $8.4(0.93)$ & & & \\
\hline \multicolumn{6}{|l|}{ Family history of congenital anomalies } \\
\hline Negative & 91 & $8.4(0.98)$ & -0.47 & -0.91 to -0.03 & 0.038 \\
\hline Positive & 6 & $8.8(0.41)$ & & & \\
\hline \multicolumn{6}{|l|}{ At least one phone call } \\
\hline Negative & 38 & $8.3(1.01)$ & -0.21 & -0.61 to 0.19 & 0.294 \\
\hline Positive & 59 & $8.5(0.94)$ & & & \\
\hline
\end{tabular}

Table 5: Median count of ANC visits split by group and compared via a Mann-Whitney test.

\begin{tabular}{lrr}
\hline & Controls $(\mathrm{n}=146)$ & Intervention $(\mathrm{n}=\mathbf{9 7})$ \\
\hline Count of visits & & \\
Range & $1-9$ & $1-12$ \\
Median & 2 & 4 \\
Inter-quartile range & $1-3$ & $3-6$ \\
\hline
\end{tabular}

$\mathrm{P}<0.001$.

housewives; this was reflected in this study, where only $10.3 \%$ of the intervention group reported using the Internet. This makes mobile phone technology an excellent alternative.

This text messaging technology was found to be feasible; the time and effort spent by the provider of the service was reasonable, and it would have been little further work to send messages to an even larger population. It was also shown to be a low-cost method: each message cost $\$ 0.0225$ at the time of the current study, while a text message ordinarily costs $\$ 0.1$ (4 times the cost in this text message project).

Based on the satisfaction questionnaire, the frequency of women with high satisfaction (agree/strongly agree with the tested item) was highest (>85\%) for "The client recommends this program for other pregnant women", "Personal rating for the message as a whole", "They obtained benefit from the messages" and "They would like to be engaged in the same program in their subsequent pregnancies". It did encourage the participants to visit the PHCC and most participants welcomed the text messages; some wrote positive comments, for example, "Well thank you for your messages that change a lot of wrong information that I have towards my pregnancy", "I used to finish my work early every Friday waiting for your message". 
Table 6: Poisson regression model with count of ANC visits as the response (dependent) variable and the effect of intervention (SMS health messages) and educational level as the explanatory (independent) variables.

\begin{tabular}{|c|c|c|c|c|}
\hline & Mean $^{\mathrm{a}}$ & $95 \% \mathrm{Cl}^{\mathrm{a}}$ & Wald chi-square ${ }^{\mathrm{b}}$ & P-value \\
\hline \multicolumn{5}{|l|}{ Group } \\
\hline Intervention & 4.19 & $3.78-4.59$ & 44.960 & $<0.001$ \\
\hline Control & 2.55 & $2.28-2.82$ & & \\
\hline \multicolumn{5}{|l|}{ Educational level } \\
\hline Primary school and below & 3.64 & $3.24-4.03$ & 8.329 & 0.004 \\
\hline Intermediate school and above & 2.94 & $2.65-3.22$ & & \\
\hline
\end{tabular}

${ }^{\mathrm{a}}$ From estimate marginal means.

${ }^{\mathrm{b}}$ From model.

Age and parity had no important or statistically significant contribution to the model as explanatory (independent) variables.

Omnibus test for difference of model from an intercept-only model, $\mathrm{P}<0.001$, Akaike information criterion =920.171.

Another indicator of the acceptability of this project and its interactive advantages was the 314 phone calls that were received from the intervention group; some women were keen to continue communicating with the service providers even after the deadline of the study was announced (time of delivery).

Although the reminder texts were the least preferred text type, they may have influenced the statistically significant increase in the number (around two visits per pregnancy) of ANC visits, probably encouraging women to attend at certain times in their pregnancy.

This is the first report of using text messaging in the provision of antenatal healthcare of Iraqi pregnant women. Previous published articles have supported the view that a higher count of ANC visits is associated with better outcomes of pregnancy. This view was further tested in low-resource countries; Asundep et al. [15] concluded that $<4$ ANC visits was associated with an increase in adverse outcomes of pregnancy using adjusted models. Riaz et al. [16] showed that pregnancies with $\geq 3$ ANC visits were associated with far better and healthier outcomes than those with <3 visits, in Pakistan; moreover, the WHO's latest recommendations that had been released on 7 November 2016 in Geneva stated that a minimum of eight visits for ANC can reduce perinatal deaths by up to 8 per 1000 births when compared to a minimum of four visits [17].

The two comparison groups were homogenous in comparison with respect to known confounders like age, employment status and parity, apart from the possible confounding effect of educational level on the outcome, which was adjusted for by the Poisson regression model. The multivariate model showed that higher education is associated with a lower mean count of ANC visits. This finding complies with the authors' expectation that women with a higher educational level would experience fewer visits to the PHCC, as they tend to be less satisfied by the quality of services provided at these public centers and generally seek advice at private clinics. This view is shared by Iraqi obstetricians working in the public health services sector. In addition, women with lower education are at greater risk of pregnancy complications, so this m-Health intervention may improve the pregnancy outcomes in this less-privileged population sector.

Our program may offer a new approach to improve ANC services in Iraq. The latest report from the Iraqi Ministry of Health showed underutilization of ANC services by pregnant women, which could be attributed to an absence of awareness about the importance of these services or a lack of confidence in the services available.

The result of this study was comparable with a randomized controlled trial (RCT) conducted in Malaysia using text messaging to improve attendance in primary care: the attendance rate of the text messaging reminder group was significantly higher and the cost of the text messaging reminder was also reasonable, being $\$ 0.09$ per patient [18]. The same positive result has also been demonstrated in young diabetic people engaged in the Sweet Talk text messaging system trial, where $82 \%$ of patients improved their diabetes self-management and $90 \%$ wanted to continue receiving messages [19].

Though our text massages had other tasks, their main target was to work as a reminder to attend the PHCC on the scheduled time. In Thailand, automated SMS-based reminders to 280 pregnant women have been shown to increase the number of on-time prenatal care visits by a factor of 1.9 in women who received reminders [20]. In Australia, appointment reminders for attendance at outpatient clinics sent as SMS text messages to patients' mobile telephones has been shown to significantly lower overall failure-to-attend rates $(14.2 \%$ vs. $23.4 \%$; $\mathrm{P}<0.001)$. 
Based on this result, the authors plan to extend the trial of SMS reminders to all outpatient clinics in their hospital [21]. Measuring on-time attendance will be one of our targets in a future study.

General health messages, nutritional advice and lifestyle education were the preferred types of messages, which were indicated as the preferred content, exceeding the preference for text reminders. This finding, when viewed in association with the high count of phone calls received by the help center in relation to pregnancy problems, labor information and puerperium, may provide another clue for the acceptability of this $\mathrm{m}$-Health project. The educational role of this electronic method was also shown in other studies. One successful program that is being broadly disseminated in the United States is the "text4baby" program, which sends weekly free text messages to help new and underserved mothers to get access to information that they need to take care of their own health and that of their babies [22].

The explanatory variables taken into consideration in our study failed to show any significant relationship with the positive impact of the messages, apart from family history of congenital anomalies. Future m-Health interventions might therefore be designed to focus on those with a poor obstetric history.

This pilot study showed that mobile-phone-based pregnancy support is feasible, reasonably acceptable by Iraqi pregnant women, of low cost and encourages their ANC visits. Larger randomized studies are needed to provide evidence for extended services with the probable use of an SMS appointment reminder system to improve antenatal visits, to rate the quality of services at the PHC level and, as some women commented that they wished to have more customized communication, to suggest personalized messages tailored to patients' needs.

Acknowledgments: The authors wish to thank the Al-Kindy Medical School at the University of Baghdad for supporting this project. They also wish to thank The British Council for its grant to develop collaborative links between UK universities (Kingston University, London, and Cardiff University, Cardiff) and Iraqi universities (Baghdad and Basrah Universities) as part of the DelPHE Iraq project. They also grateful to Dr. Nazar S. Haddad for his general contribution to the study design.

\section{Author's Statement}

Conflict of interest: Authors state no conflict of interest. Material and methods: Informed consent: Informed consent has been obtained from all individuals included in this study.
Ethical approval: The research related to human use has been complied with all the relevant national regulations, institutional policies and in accordance the tenets of the Helsinki Declaration, and has been approved by the authors' institutional review board or equivalent committee.

\section{References}

[1] Global Mobile Statistics 2014 Part A: Mobile subscribers; handset market share; mobile operators by International Telecommunication Union (May 2014). Available at: https:// mobiforge.com/research-analysis/global-mobile-statistics2014-part-a-mobile-subscribers-handset-market-share-mobileoperators.

[2] Istepanian RSH, Woodard B. M-health fundamentals and applications. Hoboken, New Jersey, USA - IEEE: John Wiley \& Sons, Inc.; 2016.

[3] World Bank 2012 Report. Available at: http://data.worldbank. org/sites/default/files/wdi-final.pdf.

[4] The World Health Report 2006 - working together for health./ Using modern communication technology to improve data, services and productivity. Available at: http://www.who.int/ whr/2006/en/.

[5] World Health Organization: World Health Statistics. Geneva 2010. Available/Summary of status and trends. At: http:// www.who.int/gho/publications/world_health_statistics/ EN_WHS10_Full.pdf.

[6] InfoDev. Improving health, connecting people: the role of ICTS in the health sector of developing countries. InfoDev, World Bank, 31 May 2006. Available at: http://www.popline.org/ node/185203.

[7] Gerber B, Stolley M, Thompson A, Sharp L, Fitzgibbon M. Mobile phone text messaging to promote healthy behaviors and weight loss maintenance: a feasibility study. Health Inform J. 2009;15:17-25.

[8] A Basic Health Services Package for Iraq. Ministry of Health January 2009, With the Technical Support from the WHO. Funding UNDG ITF - EUROPEAN FUND/Referral system between primary and secondary care. Available at: http://applications. emro.who.int/dsaf/libcat/EMROPD_2009_109.pdf.

[9] Istepanian R, Jovanov E, Zhang Y. m-Health: beyond seamless mobility for global wireless healthcare connectivity-editorial. IEEE Trans Inform Technol Biomed. 2004;8:405-14.

[10] Mechael P, Batavia H, Kaonga N, Searle S. Barriers and gaps affecting mhealth in low and middle income countries: policy white paper. The Earth Institute Columbia University and m-health Alliance, May 2010. Available at: http:// www.globalproblems-globalsolutions-files.org/pdfs/ mHealthBarriersWhitePaper.pdf.

[11] WHO Millennium Development Goals (MDGs). Available at: http://www.who.int/topics/millennium_development_goals/ maternal_health/en/index.html.

[12] UNICEF. State of the World's Children, 2012. Available at: http://www.unicef.org/sowc2012/.

[13] Tamrat T, Kachnowski S. An analysis of mHealth in maternal and newborn health programs and their outcomes around the world. Matern Child Health J. 2012;16:1092-101. 
[14] M Health: new horizons for health through mobile technologies: second global survey on e Health, WHO 2011. Available at: http:// www.who.int/goe/publications/goe_mhealth_web.pdf.

[15] Asundep NN, Jolly PE, Carson A, Turpin CA, Zhang K, Tameru B. Antenatal care attendance, a surrogate for pregnancy outcome? The case of Kumasi, Ghana. Matern Child Health J. 2014;18:1085-94.

[16] Sultana A, Riaz R, Tehseen I, Sabir SA. Assessment of pregnancy outcome with and without antenatal care. Pak J Med Res. 2010;49:1-3.

[17] WHO, news release, 7 November 2016|GENEVA, http://www. who.int/mediacentre/news/releases/2016/antenatal-careguidelines/en/.

[18] Leong KC, Chen WS, Leong KW, Mastura I, Mimi O, Sheikh MA, et al. The use of text messaging to improve attendance in primary care: a randomised controlled trial. Fam Pract. 2006;23:699-705.
[19] Franklin VL, Waller A, Pagliari C, Greene SA. A randomized controlled trial of Sweet Talk, a text messaging system to support young people with diabetes. Diabet Med J. 2006;23:1332-8.

[20] Kaewkungwal J, Singhasivanon P, Khamsiriwatchara A, Sawang $S$, Meankaew P, Wechsart A. Application of smart phone in "Better Border Healthcare Program": a module for mother and child care. BMC Med Inform Decis Mak J. 2010;10:69-12.

[21] Downer SR, Meara JG, Da Costa AC. Use of SMS text messaging to improve outpatient attendance. Med J Aust. 2005;183:366-8.

[22] National Health Mothers- Healthy Babies Coalition: text4baby. 2011. Available at: http://en.wikipedia.org/wiki/ National_Healthy_Mothers,_Healthy_Babies_Coalition_ (HMHB)\#text4baby.

Supplemental Material: The online version of this article (DOI: 10.1515/jpm-2016-0127) offers supplementary material, available to authorized users. 